\title{
Cuidador de idosos: conhecimento disponível na base de dados LILACS
}

\author{
Elderly caregiver: the knowledge available in LILACS database
}

Cuidador de ancianos: conocimiento disponible en la basis de datos LILACS

\section{Leidimar Cardoso Nascimento', Eronice Ribeiro de Moraes', Jaqueline Carvalho e Silva', Laurimary Caminha Veloso', Andréia Rodrigues Moura da Costa Vale ${ }^{1}$}

'Universidade Federal do Piauí. Teresina, PI

Submissão: $13 / 03 / 2008$

Aprovação: 31 1/07/2008

\section{RESUMO}

O estudo objetivou analisar a produção científica sobre o cuidador de idoso. Foi utilizada como abordagem metodológica a revisão bibliográfica na base de dados LILACS, no período de 2000 a 2007. Analisou-se os resumos de sessenta e Quatro artigos sendo categorizados pelo ano de publicação, cenário, metodologia abordada e temática apresentada. Como resultado, foi observado Que em 2004 ocorreu o maior número de publicações, destacando a região sudeste, Quanto ao cenário à prevalência de escolha foi o domicílio e a abordagem metodológica foi a do tipo Qualitativa, sendo as temáticas agrupadas em Quatro áreas a seguir: cuidado ao idoso institucionalizado, a família e o cuidado ao idoso, o cuidado e suas implicações éticas e idoso e o cuidado de enfermagem.

Descritores: Idoso; Cuidadores; Família; Enfermagem.

\section{ABSTRACT}

This study aimed at analyzing the scientific production about the elderly assistance. Bibliographic review was utilized as a methodological approach based on 2000-2007 LILACS data base. Sixty-four abstracts of the articles were analyzed and categorized per year of publication of the scenery and the methodology and theme presented. As a result, it was noticed that in 2004 there was the largest number of publications, prevailingly in the Southeast of Brazil. As to the scenery, the prevalence of choice was the domicile and the methodological approach was that of Qualitative type with the themes grouped into four areas, as follows: institutionalized elderly care, the family and the elderly care, care in its ethical implications, elderly people and nursing care.

Descriptors: Aged; Caregivers; Family; Nursing.

\section{RESUMEN}

Este artículo visó analizar la producción científica sobre la asistencia a los ancianos. Se utilizó como metodologia revisión bibliográfica en la base de datos LILACS, entre 2000 hasta el 2007. Sesenta y cuatro resúmenes de los artículos fueran clasificados por año de publicación, el escenario, la metodología enfocada y el tema presentado. Como resultado, se observó el mayor número de publicaciones en 2004, predominantemente en el sureste de Brasil. Cuanto al escenario la prevalencia de la elección fue el domicilio y el enfoQue metodológico es del tipo cualitativo, con los temas agrupados en cuatro áreas, a continuación: el cuidado de los ancianos institucionalizados, de la familia y de los ancianos, la atención y sus implicaciones éticas y atención de enfermería.

Descriptores: Anciano; Cuidadores; Familia; Enfermería Geriátrica. 


\section{INTRODUÇÃO}

O Brasil atualmente vivencia um momento de transição demográfica, em virtude, principalmente, do aumento progressivo da população de idosos. Hoje, existem aproximadamente 18 milhões de idosos no país, Que equivale a $10 \%$ da população(1). As melhorias das condições de vida, juntamente com a Queda da natalidade são responsáveis pela expressiva ampliação dessa população Que apresenta maior vulnerabilidade, evidenciado por um aumento da prevalência de agravos e incapacidades.

Essas transformações do perfil demográfico e epidemiológico da população brasileira têm ocasionado o aumento de doenças crônicodegenerativas, Que eventualmente podem comprometer a autonomia do idoso, exigindo cuidados permanentes por parte da família cuidadora. Desse modo, a promoção integral da saúde e o suporte aos cuidadores familiares representam novos desafios para o sistema de saúde brasileiro.

Na gerontologia, existe um consenso de que o cuidado pode ser implementado tanto pela família como pelos profissionais e instituições de saúde. Nesse contexto, surge a figura do cuidador, o indivíduo que presta cuidados para suprir a incapacidade funcional temporária ou definitiva. Entretanto, segundo o vínculo, os cuidadores recebem diferentes denominações. Assim, os cuidadores formais compreendem todos os profissionais e instituições Que realizam atendimento sob forma de prestação de serviços e cuidadores informais, os familiares, amigos, vizinhos membro da igreja, entre outros ${ }^{(2)}$.

Estudos no Brasil e no mundo apontam Que os cuidados prestados ao idoso no domicílio são realizados geralmente por cônjuges e filhas, o Que remete às mulheres, o papel de "grandes cuidadoras", a Quem foi atribuído esse papel cultural e social, ao cuidar dos filhos, marido e familiares. No entanto, é importante ressaltar Que, como as mulheres vivem mais, compete a elas a tarefa de cuidar do esposo ${ }^{(3)}$.

A dinâmica do cuidar da pessoa idosa no contexto familiar pode gerar ambigüidades reveladas por satisfação e conflitos entre esses entes. Nesse caso, a satisfação é observada Quando as famílias estão estruturadas emocionalmente e economicamente para acolher o longevo. Por outro lado, Quando esses recursos são insuficientes podem desencadear tensão no meio familiar ${ }^{(4)}$. Estes conflitos vivenciados por cuidadores e idosos são gerados pela sobrecarga de trabalho, perda de poder aquisitivo e o fato da cuidadora ser idosa, tendo como repercussões o isolamento social, adoecimento dos cuidadores, bem como os maus-tratos em idosos.

Diante dessa realidade, torna-se essencial o desenvolvimento de estudos e pesquisas centradas na área da enfermagem, com enfoque no cuidador de idoso, especialmente o informal, considerando-se Que este, no desenvolver do seu papel, expressa sua importância manifestando-se como elo entre a família e o serviço de saúde, embora se perceba carências de recursos de suporte formal e implementações de políticas públicas que amparem esse cuidador, pois na sua rotina diária pode desencadear agravos de saúde.

Partindo desse pressuposto, apresenta-se como problema de pesQuisa: Qual a produção técnica-científica relacionada à área de saúde, em especial, da Enfermagem sobre cuidadores de idosos? Com base nesse Questionamento, constitui objetivo deste estudo: levantar a produção técnico-científica relacionada à área da Enfermagem acerca do tema "cuidador de idoso".

Este estudo se justifica, tendo em vista a nova realidade em Que circunscreve o idoso em nossa sociedade atual, o Que impõe a urgência de mudanças e inovação das políticas públicas de atenção à saúde do idoso, bem como de seu cuidador.

Além disso, a partir do enfoque apresentado, este estudo será capaz de motivar novas pesquisas e poderá contribuir também para Que os profissionais enfermeiros possam refletir de forma consciente sobre suas ações e atitudes no cuidado com o idoso, no sentido de possibilitar o desenvolvimento de práticas holísticas, reflexivas e capazes de subsidiar a assistência do cuidador de idosos.

\section{METODOLOGIA}

Trata-se de um estudo bibliográfico, no Qual foi realizado um levantamento da produção científica relacionada ao cuidador de idoso na base de dados LILACS, referente ao período de 2000 a 2007. Para tanto, foram utilizados os seguintes descritores: cuidador idoso. $\mathrm{Na}$ busca, foram detectados 78 artigos relacionados ao tema nesta base de dados.

Após esta etapa foi executada a leitura dos resumos e, por conseguinte, foram analisadas e selecionadas as pesquisas de interesse para este estudo, conforme a apresentação do enfoQue temático, período de publicação, cenário da pesQuisa, metodologia aplicada e unidade da federação. Dessa forma, após análise, foram excluídos da pesquisa Quatorze artigos por não atenderem aos critérios prévios de inclusão, nove destes foram publicados antes do ano 2000 e cinco não se enQuadravam à temática.

Ao término do recorte dos dados, ordenamento do material e classificação por similaridade semântica, as temáticas foram agrupadas conforme semelhança de conteúdo, as Quais foram distribuídas em Quatro categorias temáticas para serem discutidas e analisadas em seguida.

Este estudo originou nas seguintes categorias temáticas: cuidado a idosos institucionalizados; a família e o cuidado a idosos; cuidado e suas implicações éticas; e idoso e o cuidado de enfermagem.

\section{RESULTADOS E DISCUSSÃO}

A produção científica referente à problemática do cuidador do idoso adouire cada vez mais o interesse dos pesquisadores e apresenta grandes avanços na área da geriatria e saúde pública, embora denote um tema relativamente recente. Nesse sentido, este estudo contemplou a produção científica mais recente da Enfermagem sobre o cuidador de idoso.

Para a realização da análise e discussão dos dados identificados após a leitura dos resumos, levou-se em consideração o ano, o cenário, a metodologia, a unidade da federação e a temática. E partindo dessas variáveis, foi possível constatar os seguintes resultados. Das sessenta e Quatro produções científicas levantadas no banco de dados LILACS, concernentes ao cuidador de idoso, destacam-se os anos de 2001 e 2007 como os de menor produção, considerando-se que apenas dois artigos foram publicados nesse período. Por outro lado, evidenciou-se Que os anos de 2004 e 2006 retrataram a maior produção científica sobre a problemática.

No Que concerne ao cenário da publicação adotado pelos pesquisadores, destaca-se, principalmente, o domicílio como o local de escolha com trinta e dois estudos, revelando o dimensionamento da preocupação dos profissionais da área da saúde com a Qualidade 
do cuidado prestado ao idoso no contexto familiar.

Os demais cenários de cuidado apontados distribuíram-se da seguinte forma: dez pesquisas a nível ambulatorial, sete em ambiente hospitalar, Quatro na instituição asilar. Nesse sentido, ressalta-se Que essas pesQuisas são resultantes, conforme descrição dos autores, do grau variável de dependência e exigências de identificação individualizada das necessidades apresentadas pelo idoso. Contudo, há ainda Que se considerar Que onze trabalhos não apresentaram a informação Quanto ao cenário.

Em relação às abordagens metodológicas utilizadas nas sessenta e Quatro produções científicas, prevaleceu a pesQuisa Qualitativa, com um total de Quarenta e oito artigos Que se utilizaram desse tipo de abordagem. As demais, treze pesQuisas, empregaram a abordagem Quantitativa, ao passo Que duas eram Quanti-Qualitativa e uma não apresentava informação esclarecedora.

De acordo com a análise dos dados coletados, a distribuição geográfica por unidade da federação, destacou-se o Rio de Janeiro e São Paulo como os estados de maior produção científica, estes, com dezesseis e dezoito artigos, respectivamente.

As temáticas focalizadas nestas produções destacam-se o cuidado ao idoso institucionalizado, com dezesseis publicações; a família e o cuidado ao idoso, com trinta e sete artigos; o cuidado e suas implicações éticas, com apenas Quatro produções e idoso e o cuidado de enfermagem, com sete trabalhos.

\section{Cuidado ao Idoso Institucionalizado}

Em estudos realizados sobre a instituição asilar e o cuidador familiar idoso, foram revelados Que, mediante as representações extraídas, há um consenso de Que a família cuida melhor do seu idoso, impedindo o surgimento de agravos. Nesse sentido, a família só lança mão da institucionalização do seu ente, Quando não dispõe de um cuidador familiar ou Quando o idoso está muito dependente, necessitando de cuidados especiais.

A aceitação de institucionalização é vista e sentida de forma contraditória, ora é apreciada com rejeição, pois frequentemente é associado ao abandono, confinamento e exclusão social gerando reflexos negativos na sociedade, mas para outros, configura uma possibilidade, caso o cuidado, por alguma razão, não possa ser executado no domicílio.

\section{A família e o Cuidado ao Idoso}

Decorrente do aumento progressivo da população idosa, atualmente, concretiza-se o resgate do papel dos cuidadores de idosos Que, inicialmente, é visto como aquele que presta cuidados à pessoa idosa no domicílio, com ou sem vínculo familiar, e Que não é remunerado. Desenvolvem tarefas envolvendo o acompanhamento nas atividades diárias, como auxílio na alimentação, higiene pessoal, medicação de rotina, entre outros, auxiliando-o na recuperação e na Qualidade de vida dessas pessoas ${ }^{(5)}$.

No cenário domiciliar, estudos mostram Que a esposa é, com freqüência, a cuidadora primária de idosos, seguida da filha. E Que o ato de cuidar, dentro de sua complexidade, gera sentimentos diversos e contraditórios, como: medo, angústia, cansaço, tristeza e choro. Esses sentimentos devem ser compreendidos, fazendo parte da relação entre cuidador e a pessoa cuidada, devendo-se ainda, avaliar a presença de fatores estressantes entre esses cuidadores, haja vista Que, o estresse pode fomentar risco de ocorrência de situações de violência contra os idosos ou de adoecimento do próprio cuidador.

Outra Questão a ser destacada, envolve a sobrecarga de funções compreendidas nas vinte e Quatro horas diárias dispensadas na responsabilidade do cuidar, considerando-se que por exigir cuidados especiais e grande atenção, o idoso muitas vezes, dependente de sua trajetória de vida e estado de saúde, requer uma dedicação exclusiva.

Nessa perspectiva, a família é fundamental no processo de prestação de cuidado ao idoso, contribuindo para a humanização da assistência e a construção de um ambiente favorável para a recuperação da saúde do idoso, evitando, na medida do possível, hospitalizações, asilamentos ou outras institucionalizações ${ }^{(6)}$.

\section{O Cuidado e suas Implicações Éticas}

Os conhecimentos e ações sobre a ética se inserem no contexto desta problemática, o cuidador do idoso, como fator indispensável, de maneira que a assistência prestada ao idoso, seja ela, pelo profissional de enfermagem ou pelo cuidador familiar, deve estar baseada nesse princípio, a fim de Que, sejam realizados cuidados respaldados no respeito, no afeto e na sensibilidade, com o intuito, não apenas de curar a doença, mas de promover a saúde desse indivíduo.

Cabe então ressaltar o conceito de ética, como sendo derivado do termo grego éthos, Que significa modo de ser, conduta de vida ou caráter $^{(7)}$. A ética, portanto, tem o propósito de refletir o agir humano e de compreender os critérios e valores Que orientam a realização dessas ações.

Dessa forma, no que se refere ao cuidado do idoso, a ética envolve muito mais do Que legislações e normas Que permeiam a realização dos cuidados. Ela exige reflexões por parte do cuidador, seja ele profissional ou não, na tomada de decisões relacionadas às ações realizadas com os idosos, levando-se em consideração, também, a autonomia e o respeito ao idoso ${ }^{(8)}$.

\section{Idoso e o Cuidado de Enfermagem}

A assistência de Enfermagem ao idoso é dispensada tanto no ambiente institucional, como no domiciliar e objetiva atender às necessidades básicas afetadas desse grupo, para conceder-lhe melhor Qualidade de vida ${ }^{(9)}$. A enfermagem busca criar um ambiente Que proporcione ao idoso condições adequadas para sua recuperação, bem como a ênfase na educação em saúde, procurando promover a redução da morbi-mortalidade.

Um ambiente de cuidado é aQuele em Que prevalece o respeito, a confiança, a atenção, o reconhecimento e a aceitação das pessoas com suas limitações e dificuldades, buscando oferecer-lhes apóio e ajuda ${ }^{(10)}$.

O cuidar de enfermagem é uma prática complexa e por isso não pode ser pensada como um ato Que envolve somente o domínio de técnicas e tecnologias, mas como uma ação Que abrange a complexidade do lidar com o outro ser humano ${ }^{(1)}$. Os idosos apresentam necessidades diferenciadas dos demais grupos com os Quais a enfermagem trabalha, pois sua própria condição orgânica dificulta o processo de recuperação dos episódios de adoecimento e os tornam mais vulneráveis a essas ocorrências.

\section{CONSIDERAÇÕES FINAIS}

Embora se trate, ainda, de uma realidade Que gera Questiona- 
mentos, o cuidador de idosos é um elemento presente no cenário assistencial brasileiro. Os achados bibliográficos revelaram Que a condição de ser cuidador denota sobrecarga de trabalho, geralmente vinculado a situações de conflitos familiares e à falta de informações necessárias ao desempenho do cuidado. Esta situação remete para a necessidade de atenção e suporte a essas pessoas, representando novos desafios para o sistema de saúde vigente no Brasil.

Nesse sentido, as ações de cuidados aos idosos devem estar pautadas no respeito mútuo entre cuidador e o ser cuidado, na busca pelo bem estar, visando um cuidado personalizado, resolutivo e com a participação efetiva do idoso, embasado nos conceitos da ética, criando condições para a existência e a melhoria da Qualidade de vida do idoso.

E assim, espera-se com este estudo, contribuir para a produção de um conhecimento Que possibilite o desenvolvimento de práticas holísticas, reflexivas e capazes de subsidiar a assistência do cuidador de idosos, além de construir um conhecimento compartilhado para uma assistência de enfermagem mais adequada.

\section{REFERÊNCIAS}

1. Veras R. Envelhecimento populacional e as informações de saúde do PNAD: demandas e desafios contemporâneos. Cad. Saúde Pública 2007; 23 (10): 2464-6.

2. Sommerhalder C. Significados associados à tarefa de cuidar de idoso de alta dependência no contexto familiar [dissertação]. Campinas (SP): Faculdade de Educação, UNICAMP, 2001.

3. Karsch UM. Idosos dependentes: famílias e cuidadores. Cad Saúde Pública 2003; 19(3): 86 I-6.

4. Diogo MJ, Ceolim, MF, Cintra FA. Orientações para idosas Que cuidam de idosos no domicílio: relato de experiência. Rev Esc Enferm USP 2005; 39(1): 97-102.

5. Mazza MMPR, Lefevre F. Cuidar em família: análise da representação social da relação do cuidador familiar com o idoso. Rev Bras Crescimento Desenvolv Humano 2005; 15(1): 1- 10.

6 Ministério da Saúde (BR). Secretaria de Políticas de Saúde. Violência Intrafamiliar: Orientações para a prática em serviço.
Brasília(DF): Secretaria de Políticas de Saúde; 2001 .

7. Thober E, Creutzberg M, Viegas K. Nível de dependência de idosos e cuidados no âmbito domiciliar. Rev Bras Enferm 2005; 58(4): 438-43.

8. Hammerschmidt K S A, Borghi A C S, Lenardt M H. Ética e Estética: envolvimentos na promoção do cuidado gerontológico de enfermagem. Texto e Contexto Enfermagem 2006; 15 (Esp): 114-24.

9. Marin MJS, Angerami ELS. Avaliação da satisfação de um grupo de idosas e cuidadores com o planejamento de alta. Rev. Bras. Enferm 2000; 53(2): 265-273.

10. Ferreira, MA. A comunicação no cuidado: uma Questão fundamental na enfermagem. Rev Bras Enferm 2006; 59(3): 327-30.

11. Waldow VR. O Cuidado na Saúde: as relações entre o eu, o outro e o cosmos. Petrópolis(RJ): Vozes; 2004. 